\title{
Analysis on Importance of Multimedia Technology Teaching in Music Theory Teaching
}

\author{
Liu Yi \\ Zhengzhou Railway Vocational and Technical College \\ Zhengzhou, Henan 450052 China
}

\begin{abstract}
Music theory is a key part of university music teaching, which is the foundation and premise of students learning overall music course and improving music appreciation and expression ability. With the development of information technology, multimedia technology has gradually applied in university music theory teaching classroom, which becomes a necessary trend of new era. It not only can change abstract theoretical knowledge into specific and vivid teaching to help students reduce difficulty, but also stimulate students' learning enthusiasm, mobilizing students' enthusiasm and improving music teaching quality. This paper mainly analyzes the necessity and important significance of multimedia teaching means in music theory teaching, in order to illustrate some tips and application principles of multimedia technology application in music theory teaching.
\end{abstract}

Keywords-multimedia technology; music theory teaching; important significance; application principle;

\section{Introduction}

With the rapid development of modern science and technology, multimedia technology is a new teaching means, which has been gradually popular in numerous universities. Based on this, simple and traditional "piano" traditional music teaching mode cannot meet university students' learning demand. Multimedia technology in new era can combine many factors such as animation and sound, and it can bring strong vision and hearing impact to students, which has been popular among university music teachers and students. Thus, if people can rationally apply in multimedia teaching means in music theory teaching classroom, it not only can improve music theory teaching quality based on enriching teaching means, but also can properly reduce learning difficulty, creating a happy learning atmosphere, which can make students better absorb theory knowledge and improve music appreciation ability.

\section{Necessity of Multimedia Technology Teaching} Means Applied in Music Theory Teaching

Multimedia technology teaching means mainly uses computer to comprehensively handle sound, image, text and video of various multimedia information, and it establishes a certain specific logical relationship between the information, which is a teaching means of making the expressed content richer and more profound. Through using multimedia technology teaching means, music teaching can be good for students' senses in a short 45-minute classroom, helping students to grasp basic music theory knowledge, in order to make great strides towards deeper level and comprehensively improve the teaching quality.

\subsection{Improving Teaching Means and Changing Teaching Mode}

Music teaching has its own unique subject features, which makes electronic teaching means become the auxiliary means of music teaching. Due to various demands of teaching, music teachers need to use various videos, recordings and other teaching equipment. Under normal circumstances, various teaching equipment makes music teachers in a chaos, which restricts teachers and influences the teaching effect of music teaching to a certain degree. After using multimedia teaching means, sound and video are set in one, so teachers can handle skillfully and it is easy for operation in explaining theoretical knowledge, which saves time greatly, and it is also a new teaching means that traditional electronic teaching means cannot realize.

In addition, multimedia technology teaching means is 
applied in music theory teaching, which can change the traditional teaching mode and make students become the main body of learning. Teachers become the guides and organizers of teaching process, and this teaching mode can truly reflect the talent requirement and cultivation goal in current society. In this new teaching mode, teachers are no longer the leading role in the teaching process, but also they give students enough space and time to organize students for autonomous learning, which can help students to correctly understand the methods and skills of music theory knowledge.

\subsection{Re-integrating Knowledge and Strengthening Infection Force}

Music theory knowledge is boring, which is the music teaching content to bore teachers and students. Both music scale, intervals, reading and harmony are key points of music teaching theory. In previous music theory teaching, teachers need to make a lot of teaching tools, and make frequent demonstrations and explanations in classroom, thus students can narrowly understand and absorb. After using multimedia teaching means, vivid image and changing images can help teachers to assist students to understand and grasp relevant knowledge points and difficult points.

In addition, in traditional music theory classroom, when appreciating music, students will have boring mood for single music or listening to teachers' playing, which makes students have a passive sense in learning, and students' attention can not be well concentrated. Thus, the teaching effect can not be ensured. The formation of a melody can not simply be the combination of notes, but also it is the bearing capacity and reflection of thought and emotion. Music appreciation with multimedia in music theory lecture can make students have various vivid images in their brain. In stimulating their music expression desire, it will let students form their own unique understanding of music in this artistic conception, in order to improve the passion of music creation. In addition, before students appreciate the music works, teachers use multimedia technology means to choose music materials for different students, and they can independently grasp the specific features of music image before students appreciate.

\subsection{Increasing Teaching Capacity and Improving Teaching Quality}

At present, in numerous university libraries, relevant music books and video materials are in shortage, and multimedia technology can make up this defect. Through the Internet, teachers can easily and quickly find the famous musicians in the world and relevant musical works materials, and they can also download various music multimedia courseware, making music theory classroom explanation not limited by time and space. In addition, through multimedia technology platform, teachers can share relevant courseware to this public platform, making limited teaching resources obtain more efficient and full use, and it can make students learn relevant music theory knowledge and appreciate course in their spare time, in order to provide convenience and improve teaching effect for them to a great extent.

\section{Important Significance of Multimedia Technology Means in Music Theory Teaching}

Multimedia technology teaching means is used for assisting music theory teaching to make sound, video and image in one. The scattered materials and abstract knowledge can be combined, which is convenient for music teachers to organize teaching and highlight teaching focus, and it is also good for students to systematically learn these theoretical knowledge, improving the ability of analyzing and appreciating music.

\subsection{Creating Music Situation and Experiencing Multi Culture}

Reasonably and correctly using multimedia technology teaching means not only can stimulate students' learning interest, but also can use scene to promote thinking and improve students' creative ability. In music teaching classroom, when appreciating music, teachers can organize proper and corresponding animation or imagine according to the music rhythm, melody and content, creating 
corresponding music situation, making students expand rich imagination and better grasping the feature of music works. In the music situation created by multimedia technology means, it can produce a powerful infection, in order to make students enjoy learning in a specific background and obtain the ideal teaching effect.

In addition, using multimedia technology teaching can make students better understand different cultures behind the music. Music diversity not only reflects in its singing method, expression form and creation technique, more importantly, it reflects in different cultural connotations.

\subsection{Injecting New Vitality and Stimulating Students' Interest}

Interest is the best teacher. If teachers want students to have interest in music theory knowledge, they must let students free from abstract and complex theoretical knowledge, feeling the true music situation. The application of multimedia technology means in music teaching can use courseware to directly display image, text and sound in front of students, creating a sound image synchronization, colorful and static combined music situation, in order to stimulate students' learning enthusiasm and make students enjoy learning.

\subsection{Expanding Students' Vision and Developing Students'} Ability

In university, an important standard of judging music course is to make students use their own experience and knowledge to understand music. Thus, in music theory teaching class, it takes this standard as the guide, trying to combine music theory knowledge and actual life, making students experience the great charm of music in life. But, for the status of a lack of university music theory knowledge, teachers should rationally use multimedia teaching means and let students have intuitive perception.

Multimedia can also express abstract knowledge vividly when expanding students' vision, in order to help students easily breakthrough key points and difficult points. For example, when students understand western musical instruments and folk instruments, teachers can help students to correctly analyze and distinguish between the instruments and the difference between different music works. This enlightenment can make students rise from abstract theory knowledge to intuitive feeling level, in order to make university breakthrough the theory knowledge of the key points and difficult points, improving teaching quality.

\section{Usage Principles of Multimedia Technology Teaching in Music Theory Teaching}

\subsection{Auxiliary Principles}

Multimedia technology teaching means is one of the teaching means, which has effective role for music theory teaching. But, multimedia technology is only an auxiliary means, and we cannot excessively strengthen its role but ignore the leading role of teachers and students' main position. Thus, in music theory teaching process, teachers should regard multimedia technology as the punch line and reasonably play its role.

\subsection{Appropriate Information Principle}

Currently, in music theory teaching classroom, too much information makes students cannot absorb effectively. Thus, students cannot absorb too much information in short period of class time, making brain easy to have stagnation state. The direct result is the "human irrigation" to "machine irrigation" teaching mode, so as to seriously influence students' main body position. Thus, multimedia application should be proper; making students can conduct deep processing under teachers' guidance, improving students' self-learning ability. Of course, while using multimedia teaching means to explain music theory knowledge to students, teachers should also give students enough time and space to let them imagine and think, so as to improve the teaching creativity.

In short, multimedia teaching of the new teaching means has incomparable advantage than traditional teaching means. Thus, using multimedia teaching to assist music theory teaching has become a common trend of university music education in China. Of course, although multimedia 
technology teaching has many advantages in music theory teaching, yet it has many problems. Thus, university teachers should also notice tips and principles in using multimedia technology, in order to reflect the superiority of multimedia teaching and also truly improve the teaching quality of university music.

\section{References}

[1] Yu Yizhi. Analysis on application of multimedia teaching means in university music theory course teaching $[\mathrm{J}] .2007,(9)$.

[2] Zhang Guoli, Liu Lili. Application of multimedia aided teaching system in music classroom[J].2011,(20).

[3] Li Dexian. Analysis on importance of multimedia aided music classroom teaching[J]. 2011,(8).

[4] Li Qun. Effect of multimedia technology in music teaching [J]. 2011,(24). 